\title{
Erratum
}

Erratum: Keitel et al., "Medial Nucleus Accumbens Projections to the Ventral Tegmental Area Control Food Consumption"

In the article "Medial Nucleus Accumbens Projections to the Ventral Tegmental Area Control Food Consumption," by Colin W. Bond, Richard Trinko, Ethan Foscue, Kara Furman, Stephanie M. Groman, Jane R. Taylor, and Ralph J. DiLeone, which appeared on pages 4727-4738 of the June 10, 2020 issue, because of a copyediting error, all instances of the words "photo-stimulation," "photoinhibition," and "photo-stimulated" incorrectly had the word "graph" added to the word "photograph." The online version has been corrected.

DOI: 10.1523/JNEUROSCI.1829-20.2020

\section{Erratum: Salido and Ramamurthy, "Proteoglycan IMPG2 Shapes the Interphotoreceptor Matrix and Modulates Vision"}

In the article "Proteoglycan IMPG2 Shapes the Interphotoreceptor Matrix and Modulates Vision" by Ezequiel M. Salido and Visvanathan Ramamurthy, which appeared on pages 4059-4072 of the May 13, 2020 issue, the links to Movie 1 and Movie 2 were transposed in their respective legends. The online version has been corrected. 